\title{
STUDY THE EFFECTIVENESS OF THE ART OF IMPLEMENTING AN EXTENSION PROGRAM ON THE FEASIBILITY STUDY ON THE DIRECTION OF UNIVERSITY STUDENTS KING ABDUL AZIZ TOWARDS SMALL PROJECTS \\ Amal Abdel-Razzaq SALAMEH* \\ Department of Housing, Faculty of Home Economics, King Abdul-Aziz University, KSA
}

\begin{abstract}
The study aimed to enhance the vision of Saudi Arabia 2030 towards empowering women by contributing to the dissemination of the culture of the importance of work for Saudi women and directing them towards the establishment and management of small projects in a scientific way, namely the art of applying the feasibility study before starting the project, Feasibility before and after the application of the indicative program, and study the impact of the application of the indicative program on their orientation towards the establishment of small enterprises. The study was followed by the experimental method. The tribal questionnaire was applied to 160 students from King Abdul Aziz. University who were studying the project management course as a freely selected material. The sample was then divided into two experimental group groups (80 students) who applied for a one-month extension program and a control group 80 students) did not apply the program, then the postquestionnaire was applied to the total sample (experimental and control) to determine the effectiveness of the applied program.

Keywords

Effectiveness, Art, Implementing, Program, Feasibility Study, King Abdul Aziz.
\end{abstract}

\section{Introduction}

The most important results of the study were the differences between the awareness of the experimental sample in the feasibility study and their orientation towards small projects before and after the application of the program in favor of the post application. There are statistically significant differences between the awareness of the experimental sample and the awareness of the control sample on the application of the feasibility study. Experimental Sample.

The study recommends directing secondary school curricula to focus on directing students to find suitable job opportunities for their skills and abilities in various increase the chances of success and continuation in the market, and raise the awareness of students on the basics of ecommerce to keep up with the technological development and its importance in support of small enterprises.

\section{Research Problem:}

Societies face great challenges in their development efforts, the most important of which is the challenge of rationalizing human energies that maximizes economic and social returns and limits negative phenomena, especially in light of the high rate of population growth. In light of the great aspirations, entrepreneurship has become a reality that constitutes hope for the future

* Corresponding author: hjambi@kau.edu.sa 
of the world, and the issue of young entrepreneurs has become a pivotal issue that requires decision-makers to take effective steps in supporting their projects and uniting efforts to overcome the difficulties they face.

Whereas the success of development and the realization of its programs are dependent on many factors such as the effective participation of all energies and work forces in society, including women who have a role in society that is no less important than the role of men, so the Kingdom has strengthened the status of women by placing gender equality and empowering women and highlighting them as an active and influential element. Among its sustainable development goals in its 2030 Vision, especially since females make up 49 percent. $6 \%$ of the total Saudi population, but their economic participation rate does not exceed $19 \%$ compared to the male participation rate of 64. Accordingly, the rate of women's participation in the labor market increased from $12 \%$ in 2009 to $18 \%$ in 2017 , and the Kingdom aims to raise the rate of women's participation to reach $25 \%$ in 2020 . The importance of small projects lies in the social, economic and environmental dimension of societies. On the social side, small enterprises transform students (especially in global education from job seekers to job creators and are linked to other crucial issues such as unemployment, marriage and the elimination of emptiness, and on the economic side, small enterprises compete with large projects as they represent Industries that feed and complement them, as well as contribute to bridging the domestic demand gap for many commodities, thus increasing the overall demand for exports and reducing the import bill. On the domestic side, small enterprises play a role in preserving the environment and its natural local resources, as a large part of it is based To recycle the waste of major industries and thus conserve depletable resources.

The art of implementing extension programs for training in preparing a feasibility study for projects is one of the most important means aimed at directing women towards selfemployment, making them aware of its importance, and providing them with the information, skills and capabilities necessary for the success of the project.

The feasibility study is the scientific planning through which we arrive at a deliberate decision to accept or reject

The investment project that he started with his idea, and embarking on the implementation of a project without adequate study may be the cause of the failure of the project due to the discovery of difficulties that result in the loss of money many times the money that can be spent on feasibility studies. It is worth noting that the feasibility study goes through two phases, the first of which is a pre-feasibility study, which is the market study to ascertain the presence of marketing potential for the product to be produced. If this study indicates the success of the 
project in principle, the study will be continued to complete the second phase, which is the comprehensive Feasibility study. study) And if the preliminary study indicated that the idea of the project was not successful, comprehensive study costs were saved, which is more expensive.

Fathi Khan's study (2014) confirms that the financial feasibility study helps in making a financing decision, rationalizing investment and directing it to the best investment alternatives, determining the profitability of the project and assessing the extent of its success in achieving its objectives.

The results of the study of both Abdul Muttalib Daleel and Abdul Latif Ali (2018) indicate that the success of the feasibility study depends on the availability of required data and information, which in turn helps in making financing decisions and thus the success of the project.

A civil study of Abu Auf (2014) also indicates that the main challenges facing businesswomen in small enterprises in the Kingdom of Saudi Arabia are strengthening the position of women in the labor market, localizing their knowledge and informatics, developing their skills in financial management, and providing capital.

From the above, the research problem arises, which is represented in answering the following question: "How effective is the application of the feasibility study program on the orientation of female students at King Abdulaziz University towards small projects, from which several questions arise, namely:

1- What is the awareness level of King Abdulaziz University students about the art of applying the feasibility study before and after the extension program?

2- To what extent do female students of King Abdulaziz University tend towards establishing small projects before and after the extension program?

Implemented program steps:

The researcher followed Pesson's method in building the extension program, which depends on two basic stages:

The first stage: planning the extension program: it includes the following:

1- Determine the general objective of the extension program: which is to educate students about the art of applying the feasibility study to establish small projects on a well-studied scientific basis that increase their chances of success.

2- Sub-objectives of the counseling program: Provide students with information and skills on: Choose the project idea and prepare an identification card.

Types of small projects and elements of project management in a scientific way. 
Types of economic, technical, marketing, and technical feasibility studies.

- The stages of building the initial feasibility study.

- Methods of addressing the obstacles facing the initial feasibility study and the development view of the project.

3- The second stage: implementing the extension program:

- Developing a plan for the advisory program: The implementation plan was drawn up in light of the previous objectives, then the training fields were formulated in the form of educational units that contain lessons, each of which aims to provide the students with the necessary information, skills, and trends.

Implementation of the extension program: The duration of the implementation of the program was a full month, at the rate of two days every week, every day 3 hours (i.e. 12 hours during four weeks). The number of female volunteer participants to attend the program is 80 students, with interaction between them and the mentor in a way that ensures increasing their insight into their projects and modifying their ideas and attitudes in a group and individual setting dominated by acceptance, understanding, support and exchange of information and skills.

First session: Choosing a project idea and preparing an identification card:

Session time: one hour for the topic of the project idea, and two hours for the topic of the identification card.

\section{Research Objectives:}

Knowledge objectives: Provide students with information on how to choose project ideas that fit the needs of the community, and information about the sections of the project identification card (the project's brand name, the project logo, the competitive idea of the project, the target group, the project site).

- Skill goals: Training students in the skill of differentiating between several ideas for different projects, and preparing an identification card for the chosen project.

- Directions: Directing students towards the importance of self-employment and small projects, by choosing each student for a project idea that fits her capabilities and specialization and fits the needs of society. And direct them towards describing the details of the project that can be implemented in the future.

- The guiding methods and means used: the lecture and the PowerPoint presentation to present the necessary information, discussion and dialogue in small groups so that each group includes students of the same specialty to propose ideas for different projects, and an individual workshop in which each student applies what he has learned in practice.

Session Two: Types of Small Projects and Elements of the Administrative Process: 
Session time: an hour for the topic of types of small projects, and two hours for the topic of elements of the administrative process.

Session objectives:

- Knowledge objectives: to provide students with information on the types of industrial, wholesale and retail commercial, agricultural, and service projects, and information on the elements of the administrative process (planning, organizing, directing, controlling).

- Skill goals: To train students in planning skills, leadership skills, communication and motivation based on guidance).

Directions: Directing students towards the importance of applying the elements of the administrative process to the success of the project.

- The guiding methods and means used: the lecture and PowerPoint presentation to present the necessary information, discussion and group dialogue.

The third and fourth sessions: Types of feasibility study:

Session time: 3 hours for the topic of the economic feasibility study and the financial feasibility study, and 3 hours for the technical feasibility study and the marketing feasibility study.

. Session objectives:

Knowledge objectives: Provide students with information on the types of feasibility studies (economic, financial, technical, and marketing).

- Skill goals: To train students in the skill of distinguishing between the requirements of each type of feasibility studies.

- Directions: Directing students towards the importance of fulfilling the feasibility study for each of its types and requirements.

- The guiding methods and means used: the lecture and the PowerPoint presentation to present the necessary information, discussion and group dialogue.

Fifth, sixth and seventh sessions: Stages of building a preliminary feasibility study:

Session time: 3 hours for the first phase (project costs), 3 hours for the second phase (project revenues) and 3 hours for the third phase (comparison of total costs with total revenues after zakat).

. Session objectives:

- Knowledge objectives: provide students with information on counting project costs (compulsory, variable and semi-variable), information on the method of calculating project revenues according to sales outlets and their multiplicity, and information on calculating the percentage of zakat from total revenues. 
Skill goals: To train female students in the skill of calculating project costs and revenues.

Directions: Directing students to choose the appropriate project that is expected to succeed in the future, according to the application of the art of the feasibility study.

- The guiding methods and means used: the lecture and PowerPoint presentation to present the necessary information, discussion and group dialogue, and individual dialogue with each student about the feasibility study that she will prepare.

The eighth session: Addressing unexpected results and the development view of the project:

. Session time: an hour and a half for the topic to address the unexpected results, and an hour and a half for the project's developmental view.

Session objectives:

- Cognitive objectives: provide the students with information on ways to address the obstacles that appeared in the feasibility study that hinder the success of the project, and information on how to predict the development and success of the project.

- Skill goals: Training students in the skill of deliberate forecasting of the extent of project success and development.

Directions: Directing students to choose the appropriate project that is expected to succeed in the future, according to the application of the art of the feasibility study.

- Guidance methods and means used: the lecture and PowerPoint presentation to present the necessary information, discussion and group dialogue, and individual dialogue with each student about her proposals to face the obstacles she faced in the feasibility study, and her proposals on increasing the percentage of sales and developing the project.

Fourth: Research results according to hypotheses:

\section{The First Hypothesis:}

1- Results of (T) test for correlated samples to indicate the differences between the students 'awareness level (experimental sample) of the art of feasibility study before and after the application of the program, it becomes clear that the value of the significance level is less than 0. 05 This means acceptance of the hypothesis, and it indicates the existence of statistically significant differences between the awareness level of the experimental sample students of the feasibility study before and after the application of the program in favor of the post application, where the arithmetic average of the post application reached 3.56, while the pre-application reached 3. 04 which indicates the effectiveness of the advisory program in raising the level of students 'awareness of the application of the feasibility study. This result is consistent with the result of the study (Regni, Rosalie 2010), which indicates that interest in educational cognitive goals when developing extension programs supports building and managing small projects and 
raises the level of knowledge of Next to establish a project.

\section{The Second Hypothesis:}

2- The results of the T-test for correlated samples indicative, the differences between the students 'orientation (the experimental sample towards small projects before and after the implementation of the program, it becomes clear that the value of the significance level is less than 0.05 , which means acceptance of the hypothesis and the existence of statistically significant differences between the orientation of the experimental sample towards small projects before After implementing the program, and from the arithmetic averages, it was found that these differences were in favor of the post application, as the arithmetic average of the post application reached 3.25, while the pre-application reached 3.33

\section{The Third Hypothesis:}

3- The results of the T-test for independent samples for the significance of the differences between the level of awareness of the students of the experimental and control samples about the art of the feasibility study. Before applying the program, it becomes clear that the value of the significance level reached 0.353 , which is a value greater than 0.05 This indicates that there are no statistically significant differences between the level of awareness of the students of the experimental sample and the level of awareness of the students of the control sample of the art of the economic feasibility study before the implementation of the program, and this means the equal awareness of the students of the experimental and control groups before the application of the program.

\section{Fourth Hypothesis:}

4- The results of the T-test for independent samples for the significance of the differences between the orientation of the students of the experimental sample and the orientation of the students of the control sample towards small projects before the implementation of the program. Table 11 results indicate that the value of the significance level reached 0.658 , which is greater than 0.05 This indicates that there are no statistically significant differences between the orientation of the experimental sample and the orientation of the control sample towards small projects before the implementation of the program, which means that the students of the two groups are equal before implementing the program.

\section{Fifth Hypothesis:}

5- It shows the value of the Pearson correlation coefficient between the students 'awareness of the art of economic feasibility study and their tendency to establish small projects. Table 13 shows that the significance level value was less than 0.05 This means accepting the hypothesis 
and indicates that there is a direct correlation between students 'awareness of the art of feasibility study and their tendency to establish small projects, as the value of the correlation coefficient between them was (0.415), and this indicates that the higher the students' awareness of the art of feasibility study, the higher the level of Direct them to set up small projects.

\section{Sixth Hypothesis:}

6- Results of the Kruskal Wells test for the significance of differences in the students 'awareness of the art of feasibility study and their orientation towards establishing small enterprises depending on the economic situation variable. Table 15 shows that the values of the significance levels were greater than 0.05 This means rejection of the hypothesis and indicates that there are no statistically significant differences in the level of students 'awareness of the art of feasibility study and their orientation towards establishing small enterprises according to the variable economic situation, which indicates the similarity of the students' awareness levels of the art of the economic feasibility study and their orientation towards establishing small enterprises regardless of their economic status .

\section{Recommendations:}

1- Directing the curricula in the secondary, directive and vocational education stages to give attention to directing female students towards small projects to find job opportunities suitable for their skills and abilities in various specializations, and to give them a simple idea of the basics of preparing a preliminary economic feasibility study.

2- Developing a vision and strategy that enables the university graduate to establish and manage her project on her own in a scientific and thoughtful way to overcome the obstacles that she may face and take advantage of the available opportunities. - Raising the students 'awareness of the importance of preparing a feasibility study before starting the project to increase the chances of its success and continuation in the market.

\section{References:}

1- The First National Voluntary Review (2018) towards sustainable development of the Kingdom of Saudi Arabia, Vision 2030, Ministry of Economy and Planning, Kingdom of Saudi Arabia.

2- The Chamber of Commerce and Industry in Riyadh (2010) Towards Identifying Problems and Challenges Facing Young Businessmen in the Saudi Economy, a working paper submitted to the Riyadh Economic Forum, in the Chamber of Commerce and Industry in Riyadh.

3- Khalil Attia (2008) Book of Economic Feasibility Studies, Faculty of Commerce, Assiut University, c.

4- Dina Abu Shaaban (2015) The extent of youth employing the social networking site 
Facebook "in developing creative thinking and entrepreneurship, a research published in the Leadership and Creativity Conference in Small Business Development, Islamic University, College of Commerce, Gaza, Palestine.

5- Thuqan Obaidat, Kayed Abdul Haq and Abdul Rahman Adas (2012) Book of Research, Science, Its Concept, Tools and Methods, 14th Edition, Dar Al Fikr, Amman, Hashemite Kingdom of Jordan.

6- Abd Al-Raouf Muhammad Husayn (2011), Small Business Economics Book, Jordan Book Center, Jordan.

7- Abd al-Muttalib Othman Daleel and Abd al-Latif Ibrahim Ali (2018) The importance of a feasibility study in financing infrastructure projects in Sudan, Journal of Administrative Sciences, vol. 1, p. 2, Sudan.

8- Ali Nabil (2001) Culture and the Information Age - a future vision, Arab cultural discourse, the world of knowledge, the National Council for Culture, Arts and Literature, Cairo, c.

9- Fathy Khan (2014) The importance of a financial feasibility study in financing investment projects, an unpublished master's thesis, Mohamed Khoudir University, Biskra, Algeria. . Maria Al-Maswabi (2015) Effectiveness of a proposed counseling program in developing cognitive skills among divorced women, College of Education, Department of Community Mental Health, Islamic University of Gaza, Palestine.

10- Hamid Abu Ouf (2014), Small and Medium Enterprises and their Role in Providing Job Opportunities for Female Graduates of Family Education and Home Economics (Family Sciences) in Saudi Universities, a research published in the Arab Gulf Message Magazine, M35, P133, College of Education, Taibah University, Saudi Arabia .

11- Advancing Women in the Global Marketplace New York, (5-6 March 2009. August 2010) Available on Line at: http://www.unglobalcompact.org/docs/newsEvents/Bulletin/AdvanceWomen_Report.pdf. 12- • Ndiritu Caroline, MA, Ndiritu Anne (2016) Small And Medium Enterprises Training For Survival In A CompetitiveWorld University Of Nairobi, Kidombo Harriet v12. n19«p181.

13- Noruzi, M. R. , Westover Jonathan, H., Rahimi , Gholam Reza (2010) - An -98 Exploration of Social Entrepreneurship in the Entrepreneurship Era, Asian Social Science Vol.6, No. 6 Jun.

14- Regni , Rosalie (2010) Entrepreneurship: Methods of Preparing Students in -91 a Classroom, Environment, through the use of Simulation, the Techniques of Opening a Small Business. The International Journal of Learning Vol. 16, No. 12. 
15- Sylvia Ann Hewlettand Ripa Rashid (2010) The Battlefor Famale Talent in Emerging Markets-Center for Work -Life Policy. Available on Line at: www.worklifepolicy.org/index.php/action / Purchase Page /item/314.

16- The Women SME Association (2011) - womensmeassociation .com http://www.womensmeassociation.com/Available on Line at:The First, 350 Victoria Street Toronto, Ontario Canada M5B 2K3. Generation Project. Available on Line at: Ryerson University.

17- Muhammad Ali Mahmoud NASRA, MODIFY THE JOHANNES ITTEN CIRCLE OF COLORS TO CREATE HARMONIOUS COLOR GROUPS TO DEVELOP THE TEACHING OF COLOR SCIENCE, International Journal of Education and Learning Research, Vol. 1, No. 2, 2018, pp. 4-13.

Received: February 29, 2019

Accepted: April 11, 2019 